\title{
Tocilizumab in the treatment of rheumatoid arthritis: an evidence-based review and patient selection
}

This article was published in the following Dove Medical Press journal:

Drug Design, Development and Therapy

\author{
Martina Biggioggero' \\ Chiara Crotti ${ }^{2}$ \\ Andrea Becciolini' \\ Ennio Giulio Favalli' \\ 'Department of Rheumatology, \\ Gaetano Pini Institute, Milan, Italy; \\ ${ }^{2}$ Department of Clinical Sciences \\ and Health Community, University \\ of Milan, Division of Rheumatology, \\ Gaetano Pini Institute, Milan, Italy
}

Correspondence: Ennio Giulio Favalli Department of Rheumatology, Gaetano Pini Institute, Milan Via Gaetano Pini, 920122 Milan, Italy

Tel +3925829642I

Email ennio.favalli@gmail.com

\begin{abstract}
Rheumatoid arthritis (RA) is a chronic autoimmune disease characterized by articular and systemic manifestations, such as anemia, fatigue, osteoporosis, and increased risk for cardiovascular diseases. The pathogenesis of RA is driven by a complex network of proinflammatory cytokines, with a pivotal role of IL-6 and tumor necrosis factor (TNF). The management of RA has been dramatically changed during the last years by the introduction of a treat-to-target approach aiming to achieve an acceptable disease control. Nowadays, TNF inhibitors (TNFis) are the most frequently prescribed class of biologic therapies, but the significant proportion of patients experiencing the failure of a TNFi led to the development of alternative therapeutic options targeted on different pathways. Considering the increasing number of targeted therapeutic options for RA, there is a growing interest in the identification of potential predictors of clinical response to each available mechanism of action, with the aim to drive the management of the disease toward a personalized approach according to the concept of precision medicine. Tocilizumab (TCZ) is the first humanized anti-IL-6 receptor subunit alpha (anti-IL-6R) monoclonal antibody approved for the treatment of RA refractory to methotrexate or TNFis. TCZ inhibits both the cis- and trans-signaling cascades involving the Janus kinase-signal transducer and the activator of transcription pathway, playing a crucial role in modulating not only joint inflammation but also the previously mentioned extra-articular manifestations and comorbidities of RA, such as fatigue, anemia, bone loss, depression, type 2 diabetes, and increased cardiovascular risk. In this review, moving from pathogenetic insights and evidence-based clinical data from randomized controlled trials and real-life observational studies, we will discuss the drivers for the selection of patient candidates to receive TCZ, in order to clarify the current positioning of this drug in the treatment algorithm of RA.
\end{abstract}

Keywords: IL-6, profiling, clinical trials, efficacy, real-life

\section{Introduction}

Rheumatoid arthritis (RA) is a chronic autoimmune disease characterized by progressive joint disability, systemic inflammation, high morbidity, and increased mortality. ${ }^{1,2}$ Over the last decades, the management of RA has been dramatically changed by the introduction of a treat-to-target approach aiming to achieve an acceptable disease control defined as a state of clinical remission/low disease activity (LDA) in all diagnosed patients. ${ }^{3}$ The effective application of this strategy in the clinical practice has been facilitated by the increasing knowledge about RA pathogenesis as a process driven by a complex network of proinflammatory cytokines produced by a number of immune cells, leading to joint destruction, loss of function, and systemic manifestations, such as anemia, fatigue, osteoporosis, and increased risk for cardiovascular diseases (CVDs). ${ }^{4}$ 
The widespread release of such cytokines, including IL-6 and tumor necrosis factor $\alpha$ (TNF $\alpha)$, plays a crucial role in weighing the balance toward a proinflammatory condition, which can be effectively treated by the use of drugs targeted on the molecules actively involved in the autoimmune process. ${ }^{5}$ To date, according to the most recent international recommendations, the combination of methotrexate (MTX) with a biologic or a targeted synthetic disease-modifying antirheumatic drug (bDMARD or tsDMARD, respectively) represents the most effective approach for treating RA refractory to conventional DMARDs. ${ }^{6,7}$ Nowadays, TNF inhibitors (TNFis) are the most frequently prescribed class of bDMARDs, but the significant proportion of patients experiencing the failure of a TNFi in both randomized controlled trials (RCTs) ${ }^{8}$ and routine care ${ }^{9,10}$ led to the development of alternative therapeutic options targeted on different pathways, such as IL-6 blockade, T-cell co-stimulation inhibition, B-cell depletion, or more recently Janus-Kinase blocking. ${ }^{11}$ In particular, in vitro studies demonstrated the pivotal role of IL-6 in RA autoimmune network by contributing to $\mathrm{B}$ and $\mathrm{T}$ cells activation, acute-phase proteins and autoantibodies production, and synoviocyte and osteoclast stimulation. ${ }^{12}$ This evidence entailed the introduction of TCZ, the first humanized anti-IL-6 receptor subunit alpha (anti-IL-6R) monoclonal antibody, ${ }^{13}$ approved for the treatment of RA refractory to MTX or TNFis and widely used in clinical practice, and the more recent development of other IL-6 receptor blockers such as sarilumab. ${ }^{14}$ TCZ targets both soluble and membrane-bound IL-6R, preventing the interaction of IL- 6 with both the IL-6R and the signal transducer glycoprotein 130 complex. ${ }^{15,16}$ The result is the inhibition of both the cis- and trans-signaling cascades involving the Janus kinase-signal transducer and the activator of transcription (JAK-STAT) pathway. ${ }^{17}$

Considering the abundance of therapeutic options for RA, there is a growing interest in the identification of potential predictors of clinical response to each available mechanism of action, with the aim to drive the management of the disease toward a personalized approach based on the concept of precision medicine. ${ }^{18,19}$ The link between certain disease phenotypic manifestations and specific pathogenetic pathways has been progressively clarified, making the rheumatologist able to choose the right drug for the right patients in an increasing number of patients. ${ }^{20-22}$ As an example, IL-6 has been demonstrated to be deeply implicated not only in joint inflammation ${ }^{23}$ but also in the previously mentioned extraarticular manifestations of RA, such as fatigue, ${ }^{24}$ anemia, ${ }^{25}$ bone loss, ${ }^{26}$ mood disorders as depression, ${ }^{27}$ type 2 diabetes mellitus (T2DM), ${ }^{28}$ and increased cardiovascular risk. ${ }^{29,30}$
Moreover, results from RCTs showed the superiority of IL-6 over TNF blockade in the treatment as monotherapy of patients intolerant to concomitant MTX. ${ }^{31,32}$

In this review, moving from pathogenetic insights and evidence-based clinical data from RCTs and observational studies, we will discuss the drivers for the selection of patient candidates to receive $\mathrm{TCZ}$, in order to clarify the current positioning of this drug in the treatment algorithm of RA.

\section{From pathogenesis to clinical features: the central role of IL-6 in RA}

IL-6 is a pleiotropic cytokine mainly produced by monocytes and neutrophils upon toll-like receptors activation, with a predominant proinflammatory activity regulating both the innate and the adaptive immune system. ${ }^{33}$ Upon IL-6 stimulation, endothelial cells produce chemokines, which lead to the recruitment of other immune cells and, together with other proinflammatory mediators, to B cells stimulation and $\mathrm{T}$ cells differentiation. ${ }^{34}$ As a consequence, IL-6 promotes antibody production, by causing B cells maturation, ${ }^{35,36}$ and in concert with TGF- $\beta$ stimulates naïve $\mathrm{T}$ cells to differentiate into T helper 17 (Th17) cells ${ }^{37,38}$ and increase IL-17 production via Th17 cells. ${ }^{39}$ Moreover, IL-6 induces the secretion of acute-phase proteins, such as C-reactive protein (CRP), by hepatocytes $^{40,41}$ and activates fibroblasts-like synoviocytes, which in turn are an important source of the cytokine itself in joint synovia, and it induces autoantibody production by B cells stimulation. ${ }^{42}$ Considering all the aforementioned functions, IL-6 plays a central role in the pathogenesis of $\mathrm{RA}^{43}$ as clearly confirmed by the massive elevation of its levels both in the serum and synovial fluid of RA patients compared to healthy population, ${ }^{44-46}$ with a clear correlation with disease severity and radiologic joint progression. ${ }^{47,48}$ In particular, just from the very early phase of the disease IL-6 is crucial for the migration of neutrophils into the joints ${ }^{49}$ and for the subsequent transition from acute to chronic inflammation by increasing the recruitment of monocytes and leading to a shift from neutrophil to monocyte infiltration of the synovia. ${ }^{50}$ The persistence of articular inflammation leads to joint damage characterized by osteoclast-dependent bone erosions and cartilage narrowing produced by matrix metalloproteinases. Independent of its inflammatory effects, IL-6 is directly implicated in the activation of osteoclasts by inducing the release of RANKL by fibroblast-like synovial cells. $^{51}$

IL-6 action is the result of the interaction with a specific receptor (IL-6R) composed by a non-signaling-receptor subunit existing as both soluble (sIL-6R) and membranebound (present only on $\mathrm{T}$ cells, hepatocytes, activated 
B cells, neutrophils, and macrophages); and two signaltransducing gp130 subunits, which transduce the signal trough the JAK-STAT pathway. ${ }^{52}$ IL-6 may interact with the membrane-bound subunit in the classical (cis-) signaling pathway which activates the acute-phase response and is involved in metabolic effects, infection defense, and tissue regeneration. On the other hand, the interaction between the complex IL-6/sIL-6R and the gp130 subunits activates the trans-signaling pathway on different cells (such as endothelial, smooth muscle, and neural cells), resulting in the IL-6 proinflammatory effects. ${ }^{53}$

Moreover, the central role of IL-6 in a number of RA extra-articular manifestations and comorbidities has been definitely demonstrated. As an example, neuronal cells express gp130 subunits, so they can be stimulated by IL-6 trans-signaling, making IL-6 able to interfere with several nervous functions, such as neuronal development and survival, synaptic plasticity, ${ }^{54}$ and with central pain sensitization through the stimulation of dorsal root ganglia. ${ }^{55}$ Furthermore, hypothalamic-pituitary-adrenal axis can be influenced by IL-6 with a hypersecretion of adrenocorticotropic hormone without a reciprocal increase of cortisol. ${ }^{56,57}$ Those described effects on central nervous and endocrine systems suggest a direct role of IL-6 in generating/amplifying mood disorders and RA systemic symptoms such as pain and fatigue. ${ }^{58}$

As previously mentioned, IL-6 has been clearly associated with the induction of the acute-phase reaction including the production of hepcidin, ${ }^{59}$ which is a regulator of iron homeostasis by the inhibition of intestinal iron absorption and ferroportin-dependent iron mobilization from macrophages. ${ }^{60}$ Therefore, high IL-6 expression during sustained inflammation is a key driver in the development of anemia of chronic disease. ${ }^{61}$

Moreover, IL-6 elevation is involved in atherosclerosis, activation of endothelial cells, pro-thrombotic effects on platelets, and promotion of smooth muscle proliferation and macrophage lipid accumulation. ${ }^{62}$ As a consequence, serum IL-6 and CRP levels are associated with increased cardiovascular risk in both healthy and RA population. ${ }^{30,63}$ Finally, IL-6 has been suggested to be also involved in the pathogenesis of obesity-related and T2DM-related insulin resistance, through a complex effect on glucose homeostasis integrating central and peripheral mechanisms. ${ }^{28}$

\section{The efficacy of TCZ in the treatment of RA: main evidences from RCTs and real life}

TCZ was initially developed as an intravenous (IV) formulation, now firmly established worldwide for the treatment of RA with different recommended initial dosage regimens between Europe $(8 \mathrm{mg} / \mathrm{kg}$ body weight every 4 weeks) ${ }^{64}$ and the US (4 mg/kg every 4 weeks with the option of increasing to $8 \mathrm{mg} / \mathrm{kg}$ according to clinical response and physician's discretions). ${ }^{65}$ The development program for RA included five main randomized, double-blind, controlled, multicenter, Phase III, clinical trials conducted in different RA subpopulations. ${ }^{66-70}$ More recently, two randomized, double-blind, comparative, Phase III studies demonstrated the noninferiority of the subcutaneous (SC) formulation of TCZ ${ }^{71,72}$ which is now marketed worldwide with the exception of the US. The study characteristics of main TCZ RCTs are briefly reported in Table 1. Moreover, several observational studies reporting real-life experience with TCZ have been recently published. ${ }^{73-76}$

1. Use in combination with MTX as the first biologic agent in csDMARDs/MTX failures

The efficacy of TCZ in association with csDMARDs (including MTX) in patients who previously failed a csDMARD was evaluated in the Phase II study CHARISMA $^{77}$ and in three large Phase III RCTs (OPTION, LITHE, TOWARD). ${ }^{66,69,70}$

The CHARISMA trial included 359 patients with established, active RA refractory to MTX. American College of Rheumatology criteria for 20\% improvement (ACR20) response was achieved in 74\% of TCZtreated patients compared to $41 \%$ in the MTX arm. ${ }^{77}$ In the OPTION and LITHE trials, inadequate responders to MTX were randomized to receive two different dosages of TCZ ( 4 and $8 \mathrm{mg} / \mathrm{kg}$ ) or placebo on top of MTX. The OPTION study ${ }^{70}$ included 623 patients with active, long-standing RA, with 24-week ACR20 response as the primary endpoint, which was achieved by $59 \%, 48 \%$, and $26 \%$ of patients treated with TCZ $8 \mathrm{mg} / \mathrm{kg}$, TCZ $4 \mathrm{mg} / \mathrm{kg}$, or placebo, respectively. The proportion of patients achieving secondary endpoints, such as ACR50, ACR70, and Disease Activity Score 28 (DAS28) remission, was also significantly greater in patients in both TCZ-treated arms. ${ }^{70}$ The LITHE study including 1,196 patients with active, erosive, established RA was designed to evaluate the effect of TCZ on radiographic progression as the primary endpoint. ${ }^{66}$ Patients on TCZ $8 \mathrm{mg} / \mathrm{kg}$ achieved the lowest Genant-modified Sharp score at 52 weeks, with a mean change from baseline of 0.29 (vs 0.34 in the TCZ $4 \mathrm{mg} / \mathrm{kg}$ and 1.13 in the placebo group) and a progression from baseline reduced by $74 \%$ compared to controls. ${ }^{66}$

The efficacy of TCZ in combination with csDMARDs in patients who failed a previous treatment with 


\begin{tabular}{|c|c|c|c|c|c|c|c|c|c|c|c|c|c|}
\hline 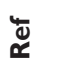 & & $\stackrel{\infty}{\circ}$ & $\stackrel{\infty}{\wedge}$ & $\pi$ & $\frac{1}{2}$ & & R & R & : & $\bar{m}$ & 으 & o & $\infty$ \\
\hline 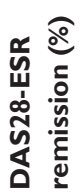 & & 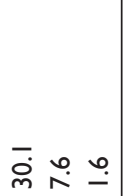 & $\stackrel{\infty}{m}$ _- & $\tilde{m}+$ & $\stackrel{m}{m}$ & & $\Sigma$ & $\hat{\sim} \stackrel{m}{\infty} \stackrel{0}{0}$ & 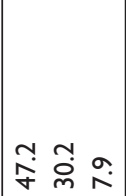 & $q=$ & o & $\AA_{m} \mathrm{~m}$ & fं \\
\hline 芯 & & $\stackrel{\dot{\Delta}}{\mathrm{I}}$ n - & 느 - & 요 n & $\stackrel{ \pm}{\sim} \quad \stackrel{\infty}{N}$ & & 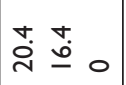 & $\approx \simeq N$ & 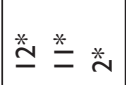 & $\stackrel{m}{m} \underline{\infty}$ & ํㅗ & $\bar{N} m$ & 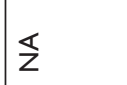 \\
\hline 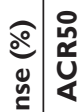 & & 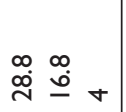 & 이 = & 우 $\simeq$ & f & & 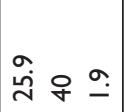 & $\forall \bar{m}=$ & 芦 总 卷 & f $\stackrel{\infty}{\sim}$ & 웅 우 & $\stackrel{\infty}{m} \sigma a$ & $\S$ \\
\hline 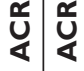 & & 요 芦 $\overline{0}$ & ํํ น & $\bar{~} \pi$ & 苛 & & $\stackrel{+}{\sim} \underset{i}{\stackrel{\infty}{\infty} \stackrel{m}{=}}$ & is $\stackrel{\infty}{+\infty}$ & 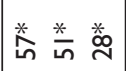 & 눙 & $\leqslant R$ & ธ & 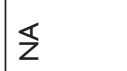 \\
\hline 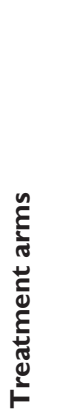 & & 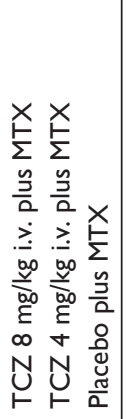 & 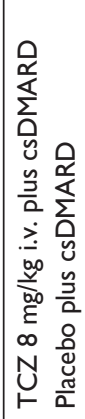 & 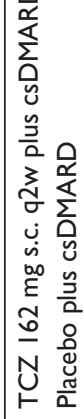 & 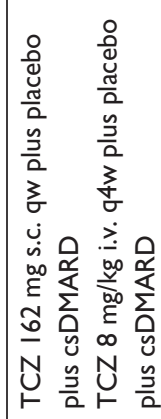 & & 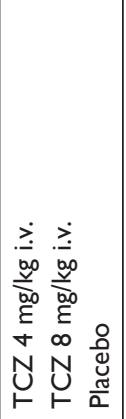 & 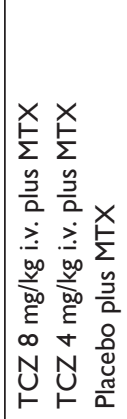 & 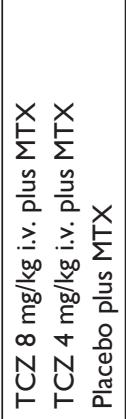 & 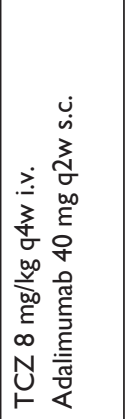 & 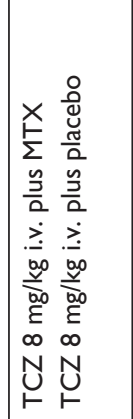 & 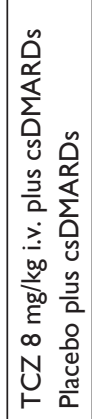 & 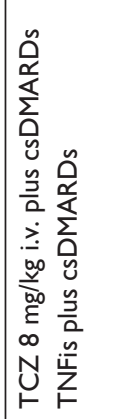 \\
\hline 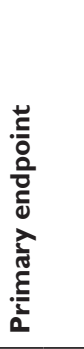 & & 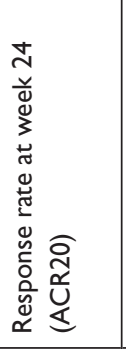 & 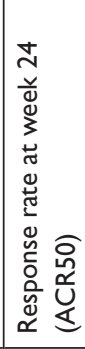 & 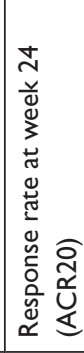 & 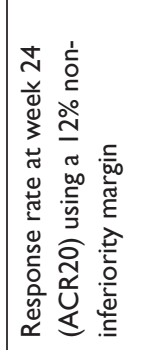 & & 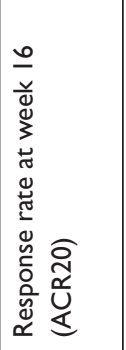 & 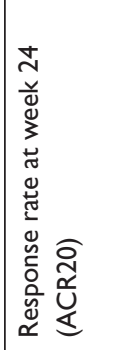 & 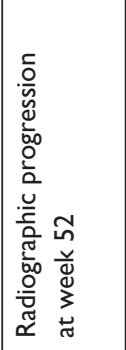 & 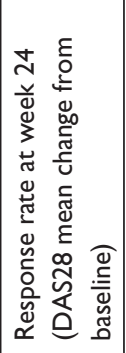 & 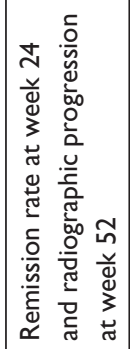 & 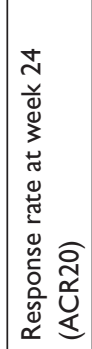 & 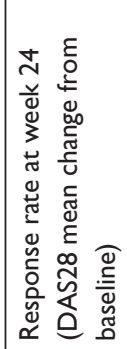 \\
\hline 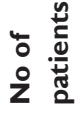 & 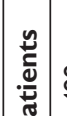 & o & $\frac{9}{6}$ & 号 & : & & 志 & స్ర & $\frac{\circ}{=}$ & $\stackrel{m}{m}$ & นึก & స్ & $\stackrel{0}{\simeq}$ \\
\hline $\begin{array}{l}\frac{5}{0} \\
\frac{\pi}{3} \\
\frac{0}{2} \\
0 \\
0\end{array}$ & 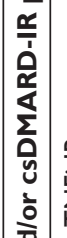 & $\begin{array}{l}\frac{\mathscr{I}}{\overrightarrow{1}} \\
\frac{\dot{L}}{\not}\end{array}$ & 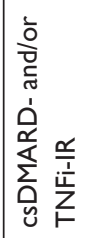 & 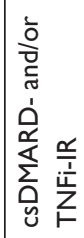 & 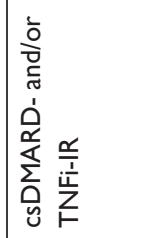 & $\mid$ & $\begin{array}{l}\frac{a}{\bar{x}} \\
\stackrel{\vec{x}}{\Sigma}\end{array}$ & \begin{tabular}{|l}
$\frac{\mathscr{x}}{\grave{x}}$ \\
$\stackrel{\underline{\Sigma}}{\Sigma}$
\end{tabular} & $\begin{array}{l}\frac{a}{\dot{亠}} \\
\stackrel{x}{\Sigma}\end{array}$ & 站 & \begin{tabular}{|l}
$\underline{\underline{x}}$ \\
$\stackrel{x}{\Sigma}$ \\
$\underline{\Sigma}$
\end{tabular} & 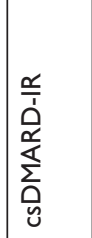 & 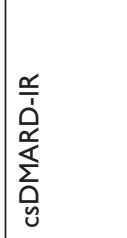 \\
\hline Ł & 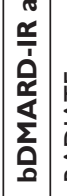 & 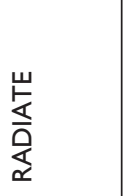 & $\begin{array}{l}\text { 岀 } \\
\propto ِ ~\end{array}$ & 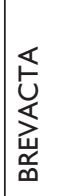 & 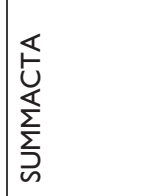 & 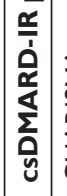 & $\frac{\frac{s}{\frac{\pi}{n}}}{\frac{\alpha}{\frac{\alpha}{\alpha}}}$ & \begin{tabular}{|l}
$Z$ \\
O \\
\\
o
\end{tabular} & 崖 & 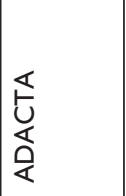 & 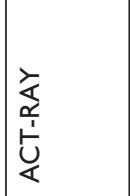 & $\begin{array}{l}0 \\
\frac{1}{4} \\
\frac{1}{3} \\
0 \\
1\end{array}$ & 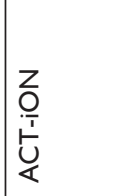 \\
\hline
\end{tabular}




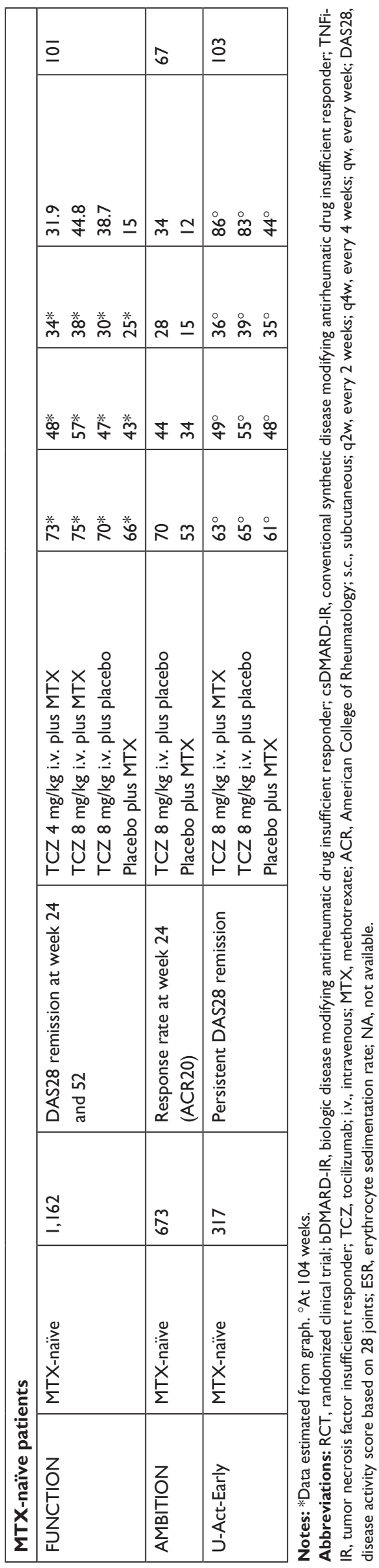

csDMARD was demonstrated in the Phase III TOWARD study, which evaluated only the more effective dose of $8 \mathrm{mg} / \mathrm{kg}$ in a population of 1,220 patients. ${ }^{69}$ ACR20 response was significantly higher in the TCZ plus DMARD group than in the control group $(61 \%$ vs $25 \% ; P<0.0001)$ and good clinical response was also confirmed according to all the considered secondary endpoints. ${ }^{69}$ These findings are consistent with the results of another similar Phase IIIb study (the ROSE trial) conducted in the same kind of RA subpopulation. ${ }^{78}$

A Cochrane systematic review of 8 RCTs including 3,334 patients $(2,233$ treated with TCZ and 1,101 controls) showed that patients receiving TCZ in combination with MTX were 4 times more likely to achieve ACR50 (38.8\% vs 9.3\%) and 11 times DAS remission (30.5\% vs $2.7 \%$ ) compared to placebo. ${ }^{79}$ Moreover, a systematic review of similarly designed clinical trial of some of the available bDMARDs (TCZ, infliximab, etanercept, adalimumab, rituximab, and abatacept) provided an indirect comparison showing that $\mathrm{TCZ}$ has the greatest estimated relative risk (RR) of ACR response compared to placebo, although the most relevant difference was observed for the ACR70 response (RR 6.8 for TCZ, 3.8 for TNFis, 4.3 for rituximab, and 3.4 for abatacept). ${ }^{80}$

2. Use in TNFi failures

The efficacy of TCZ in combination with MTX in patients who experienced an inadequate response to one or more TNFis was evaluated in the RADIATE study, including 499 patients with active RA randomized in 2 active arms (TCZ 8 or $4 \mathrm{mg} / \mathrm{kg}$ ) or placebo. ${ }^{68}$ ACR20 response was achieved in $50 \%$ and $30.4 \%$ of patients treated with TCZ 8 and $4 \mathrm{mg} / \mathrm{kg}$, respectively, and in $10 \%$ of those receiving placebo. Similarly, ACR50 and ACR70 response was also greater in patients treated with TCZ and DAS remission was significantly higher in $8 \mathrm{mg} / \mathrm{kg}$ group (30\%) compared to $4 \mathrm{mg} / \mathrm{kg}(5 \%)$ and placebo $(1.3 \%){ }^{68}$

3. SC TCZ in combination with MTX

The noninferiority of SC vs IV formulation of TCZ in combination with MTX or other csDMARDs was analyzed in the SUMMACTA trial, which enrolled 1,262 patients randomly assigned to receive TCZ SC $162 \mathrm{mg}$ weekly or TCZ IV $8 \mathrm{mg} / \mathrm{kg}$ every 4 weeks in combination with csDMARDs. ${ }^{72}$ At week $24,69.4 \%$ of TCZ SC-treated patients vs $73.4 \%$ of TCZ IV-treated patients achieved an ACR20 response (weighted difference between groups $-4.0 \%, 95 \% \mathrm{CI}-9.2$ to 1.2 ), confirming a comparable efficacy with similar safety profiles. ${ }^{72}$ Subsequently, the BREVACTA study compared TCZ 
SC $162 \mathrm{mg}$ with placebo in combination with MTX in a population of $656 \mathrm{RA}$ patients who had an inadequate response to biologic or synthetic DMARDs. ${ }^{71}$ TCZ SC was superior to placebo for 24-week ACR20 response $(60.9 \%$ vs $31.5 \% ; P<0.0001)$ and for all the secondary endpoints such as ACR50 and ACR70 response (40\% and $20 \%$ for TCZ, respectively, vs $12 \%$ and $5 \%$ for placebo, respectively; $P<0.0001$ for both) and DAS28 remission (32\% vs $4 \% ; P<0.0001)$. In addition, radiographic progression was significantly lower in TCZ compared to placebo group (mean change from baseline in the modified Sharp/van der Heijde score 0.62 vs 1.23 ; $P=0.0149) .{ }^{71}$

4. Real-life data: observational and pragmatic studies

One of the first relevant real-life experiences with TCZ was reported in an open-label study including 1,681 patients with active RA refractory to previous DMARDs. Authors observed high rates of 24-week DAS28 remission in both TNFi-experienced and TNFi-naïve patients (48.5\% and $61.6 \%$, respectively). ${ }^{81}$ These findings have been replicated in the German cohort of the ROUTINE study $(n=850)$, reporting LDA in $66.4 \%$ and DAS28 remission in $55.1 \%$ of patients. ${ }^{82}$ Moreover, the ACTLIFE study showed a similar trend in 379 patients, with more biologics-naive than biologics-experienced patients achieving 52-week good/moderate EULAR response (95\% vs $91.6 \%$, respectively; $P<0.05){ }^{83}$

Several real-life studies reported higher remission rates in TCZ compared to TNFi-treated patients. A retrospective analysis from the British Society for Rheumatology Biologic Register showed a significantly higher $(P<0.001)$ 6-month DAS28 remission in patients who received TCZ $(42 \% ; n=217)$ compared to TNFis $(28 \%$; $\mathrm{n}=2,419) .{ }^{84}$ Similar results were observed in a German cohort including 1,603 patients refractory to csDMARDs or TNFi. Despite a generally more severe disease, patients treated with TCZ achieved more frequently a clinical remission compared to TNFis, irrespective of the previous treatment (csDMARD failures: 44\% vs $29.6 \%$, respectively; TNFi failures: $41.3 \%$ vs $19.2 \%$, respectively; $P<0.001$ for both) ${ }^{85}$ Data from the Italian registry GISEA $(n=7,539,9.1 \%$ treated with TCZ) confirmed these findings, with significantly higher remission rate observed in first-line TCZ users (51\%) compared to both abatacept (23.3\%) and TNFis $(26.2 \% ; P<0.0001) .{ }^{75}$ The most relevant evidence about this topic was provided by the prospective, multicenter, comparative study ACTION, which enrolled 1,216 RA patients treated with TCZ $(35 \%)$ or a TNFi $(65 \%) .{ }^{86}$ At week 52 , the proportion of patients achieving remission was significantly higher in TCZ than in TNFi group calculated by both DAS28 (54.3\% vs 29.3\%, respectively; $P<0.001$ ) and Clinical Disease Activity Index (27.8\% vs $18.3 \%$, respectively; $P<0.001) .{ }^{86}$ Finally, data from the TOCERRA collaboration of registries (TCZ Collaboration of European Registries in RA) including 1,773 patients receiving TCZ and 4,660 receiving a TNFi showed a significantly higher crude median retention rate in TCZ combination therapy (1.98 years, 95\% CI 1.83-2.11) compared to TNFis $(1.37$ years, $95 \%$ CI $1.30-1.45) .{ }^{74}$

\section{Selection of the best patient candidate to TCZ}

The increasing number of available options for the treatment of RA within the class of targeted agents has led to the need of identifying potential predictors of clinical response in order to make therapeutic decisions according to specific drivers. However, no significant predictive factors associated with TCZ treatment have yet been demonstrated, with the only exception of the preliminary results of a subanalysis of the ADACTA trial showing that patients with lymphoid synovitis (associated with higher baseline serum $\mathrm{C}-\mathrm{X}-\mathrm{C}$ motif chemokine 13) had a better clinical response to TCZ. ${ }^{87} \mathrm{On}$ the other side, elevated body mass index and smoking have been associated with poor clinical response to TNFis $^{88,89}$ and ACPA positivity with a better response to abatacept ${ }^{90}$ and rituximab, ${ }^{91}$ but TCZ efficacy seems to be independent by all these factors. ${ }^{92-94}$ The role of serum IL-6 and acute-phase reactants such as baseline $\mathrm{CRP}$ as potential biomarkers is still controversial since opposite results were published about this topic. ${ }^{95,96}$ Of note, a recent Spanish study demonstrated that the combination between high levels of IL-6 and low levels of its receptor at baseline seems to predict a better response to TCZ. ${ }^{97}$

Similarly, a scoring system has been recently proposed to predict the efficacy of TCZ based on IL- 6 mRNA levels in the peripheral blood of RA patients before therapeutic intervention. ${ }^{98}$ However, considering the overall lack of specific biomarkers, ${ }^{99}$ the place of TCZ in the management of RA can be derived from real-life experience ${ }^{100}$ and should be searched in its peculiar mechanism of action and in the role of IL-6 in determining some RA-specific articular and extra-articular manifestations, which could be very useful as drivers for the application of a tailored approach aiming to choose the biologic drug according to clinical features of the disease.

\section{Use in very early $R A$}

As previously described, IL-6 has been demonstrated as one of the first proinflammatory cytokines implicated in 
the development of RA. ${ }^{5,49,50}$ Thus, from a pathogenetic point of view, the use of IL-6 blockers in the very early phases of the disease could be very effective. Two RCTs have been conducted with TCZ in MTX-naïve early RA patients, demonstrating the impressive effect of IL-6 blockade on clinical response and damage progression in this RA subset. The double-blind FUNCTION study enrolled 1,162 patients (mean disease duration 5 months), randomly assigned $(1: 1: 1: 1)$ to receive $4 \mathrm{mg} / \mathrm{kg} \mathrm{TCZ}+$ MTX, $8 \mathrm{mg} / \mathrm{kg}$ TCZ monotherapy, $8 \mathrm{mg} / \mathrm{kg}$ TCZ + MTX, or MTX alone (comparator group). ${ }^{101}$ The proportion of patients achieving 24-week DAS28 remission (the primary endpoint) was significantly greater $(P<0.0001)$ in all active arms $(31.9 \%, 38.7 \%$, and $44.8 \%$ in $4 \mathrm{mg} / \mathrm{kg}$ TCZ + MTX, $8 \mathrm{mg} / \mathrm{kg}$ TCZ monotherapy, and $8 \mathrm{mg} / \mathrm{kg}$ TCZ + MTX, respectively) compared to placebo (15\%). The latter group also achieved significantly higher improvement in 52-week radiographic damage progression and physical function compared to placebo (mean change from baseline in van der Heijde-modified total Sharp score [vdH mTSS] 0.08 vs 1.14, respectively; $P=0.0001$; mean reduction in Health Assessment Questionnaire Disability Index [HAQ-DI] -0.81 vs -0.64 , respectively; $P=0.0024) .{ }^{101}$ In TCZ $8 \mathrm{mg} / \mathrm{kg}+\mathrm{MTX}$ arm, the inhibition of radiographic progression was also maintained in the 104-week extension (mean change from baseline in vdH mTSS 0.19). ${ }^{102}$

The U-ACT-Early is a multicentric, randomized, double-blind, double-dummy, strategy study that enrolled DMARD-naïve patients who had been diagnosed with RA within 1 year before inclusion (mean disease duration 25 days). ${ }^{103}$ The study population was randomized to start TCZ ( $8 \mathrm{mg} / \mathrm{kg}$ ) plus MTX, TCZ ( $8 \mathrm{mg} / \mathrm{kg}$ ) monotherapy, or MTX. In the three arms a sustained 2-year DAS28 remission was achieved by $86 \%, 84 \%$, and $44 \%$ of patients, respectively $(P<0.0001$ for both TCZ groups vs MTX) and the mean change from baseline in vdH mTSS was 1.18 ( $P=0.0207$ vs MTX), 1.45 ( $P=0.0381$ vs MTX), and 1.53 , respectively. ${ }^{103}$

2. Use as monotherapy

Several reports confirmed that bDMARDs for RA are more effective when used in combination with MTX rather than as monotherapy. ${ }^{104,105}$ The main reason for this evidence seems to lie in the dampened immunogenic response to the biologic agent provided by the concomitant use of MTX, which is able to reduce the development of antidrug antibodies (mainly targeted on chimeric monoclonal antibodies) through an anti-immunoglobulin effect. ${ }^{106}$ As a consequence, international recommendations for the management of the disease strongly encourage the use of MTX as an anchor drug in association with targeted agents. ${ }^{6,7}$ Despite this clear evidence, data from observational registries suggested an unexpected widespread prescription of bDMARDs as monotherapy (up to 40\%) as the result of MTX contraindications and/or poor tolerability. ${ }^{107,108}$ Therefore, in the last decade, the identification of the best biologic treatment option for the management of patients intolerant to MTX has emerged as a crucial unmet need. Three main RCTs explored the efficacy of TCZ as monotherapy, providing the evidence for considering IL-6 blockade as the preferable strategy for this clinical condition. The AMBITION trial is nowadays the only RCT demonstrating the head-to-head superiority of a bDMARD monotherapy over MTX in RA patients who had not previously failed MTX or bDMARDs. ${ }^{67}$ The efficacy of TCZ $8 \mathrm{mg} / \mathrm{kg}$ was better than MTX according to all the considered 24-week endpoints, including ACR20 (69.9\% vs $52.5 \%$, respectively; $P<0.001$ ), ACR50 (44.1\% vs $33.5 \%$, respectively; $P=0.002$ ), ACR70 (28\% vs $15.1 \%$, respectively; $P<0.001)$, and DAS28 remission $(33.6 \%$ vs $12.1 \%$, respectively). ${ }^{67}$ Long-term results showed that efficacy was maintained or improved for up to 264 weeks in patients receiving TCZ monotherapy. ${ }^{109}$ The ACT-RAY trial was conducted in MTX inadequate responders and demonstrated that the strategy of adding TCZ to MTX or switching to TCZ monotherapy was comparable according to both clinical and radiographic endpoints. ${ }^{110}$ Interestingly, no significant difference in the incidence of anti-TCZ antibodies according to concomitant MTX was observed (1.5\% in combination arm vs $2.2 \%$ in monotherapy subgroup). ${ }^{110}$ The ADACTA trial was the first RCT head-to-head comparing two anticytokine agents with different mechanisms of action as monotherapy. ${ }^{31} \mathrm{TCZ}$ was superior to adalimumab in both the 24-week primary (mean change from baseline in DAS28 [3.3 to -1.8 , respectively; $P<0.0001]$ ) and all the secondary endpoints, with a similar incidence of adverse events (AEs). ${ }^{31}$

Real-life observational experience partially confirms the previously mentioned RCT data. The TOCERRA is a pan-European collaboration including data from ten different registries, with the aim to compare TCZ in combination with MTX vs monotherapy. Although the observed clinical response was similar between the two groups, the retention rate of TCZ as monotherapy was shorter compared to combination group after the first 1.5 years of treatment and the intergroup difference 
increased over time. These findings are consistent with the results of the recently published TOZURA trial, a multinational study program including 11 common-framework protocols that evaluated efficacy, safety, and immunogenicity of TCZ as monotherapy or in combinations with csDMARDs in RA patients. ${ }^{111}$ DAS28 remission and ACR20/50/70 response rates were similar in the two arms, but the 24-week retention rate of TCZ was significantly higher in the combination therapy group compared to monotherapy $(P=0.002) .{ }^{111}$

These clinical findings have been recently confirmed from a pharmacodynamic point of view by a study exploring the effect of the addition of MTX to TCZ, adalimumab, or tofacitinib on translational biomarkers evaluated by a cell-based BioMAP phenotypic profiling platform. ${ }^{112}$ Authors demonstrated that the BioMAP activity profile was similar for TCZ alone or in combination with MTX, whereas significant differences were observed for both adalimumab and tofacitinib. These results indicated that MTX contributes to the efficacy of adalimumab and tofacitinib, but not of TCZ, suggesting that RA therapies and can be affected by factors additional to reduced immunogenicity, ${ }^{112}$ as previously suggested by the similar incidence of anti-TCZ antibody observed between combination and monotherapy arms in the ACTRAY trial. ${ }^{110}$ In particular, considering the central role of IL-6 in the pathogenesis of RA, it is reasonable that IL-6 blockers monotherapy can be effective even without the disease-modifying support of another concomitant drug as MTX. All together, these data strongly suggest the use of IL-6 blockers in patients with contraindications/intolerance to MTX, as recommended by EULAR guidelines. ${ }^{6}$

3. The effect on extra-articular manifestations

Patient-reported outcomes (PROs) are highly valuable indicators of clinical response to therapy as patients can consider measures of health-related quality of life (HRQOL) to be more important than traditional clinimetric endpoints. ${ }^{113}$ The pivotal role of IL- 6 in the development of RA systemic symptoms like pain, fatigue, and depression has been previously described. ${ }^{114}$ Two post hoc analyses evaluating the impact of TCZ on HRQOL (including patient global assessment [PtGA], pain, HAQDI, Functional Assessment of Chronic Illness Therapy [FACIT]-Fatigue, and Short Form-36 [SF-36] physical [PCS] and mental [MCS] components) have been recently published. ${ }^{115,116}$

In the first one, PROs were explored in clinical trials where TCZ was tested as monotherapy (AMBITION and ADACTA). In the AMBITION study, 45\%-84\% of TCZ-treated patients reported MCDI compared with $39.4 \%-81.8 \%$ in MTX group. In particular, compared to the MTX group, patients receiving TCZ showed greater mean improvements in 24-week FACIT-Fatigue (5.7 vs 8.7), HAQ-DI (-0.5 vs -0.7$)$, SF-36 PCS (7.8 vs 9.8), and five SF-36 domains. In the ADACTA trial, significantly greater improvements in PtGA (-42.3 vs -31.8$)$, pain (-40.1 vs -28.7), SF-36 MCS (7.9 vs 5.0), and three SF-36 domains were observed in TCZ group compared to adalimumab. Moreover, TCZ-treated patients reported higher scores $\geq$ normative values across all PROs compared to adalimumab (22.1\%-49.3\% vs $13.6 \%-37.8 \%$, respectively). ${ }^{115}$

When used in combination with csDMARDs, both IV and SC TCZ resulted in higher proportion of patients reporting minimum clinically important differences (MCID) in PRO scores than placebo. In particular, the rates of MCID in TCZ and control groups were 50\%-82\% vs $31 \%-57 \%$ at week 16 in the OPTION study, and $54 \%-73 \%$ vs $42 \%-55 \%$ at week 12 in the BREVACTA study, respectively. Similarly, in the SUMMACTA trial, 24-week MCID was observed in 61\%-84\% and 64\%$84 \%$ of patients receiving IV or SC TCZ, respectively. ${ }^{116}$

This trend was observed even in the TNFi inadequate responders evaluated in the RADIATE trial, where the improvement of HAQ-DI values from baseline was 20.39, 20.31, and 20.05 in TCZ $8 \mathrm{mg} / \mathrm{kg}$, TCZ $4 \mathrm{mg} / \mathrm{kg}$, and control groups, respectively $(P<0.001$ and $P=0.003$ for $8 \mathrm{mg} / \mathrm{kg}$ vs control and $4 \mathrm{mg} / \mathrm{kg}$, respectively). ${ }^{68}$

These findings have been confirmed by the reallife observational experience. In the TAMARA trial (a German multicenter, open-label noncontrolled single-arm study, evaluating RA patients with moderateto-severe active disease treated with TCZ) HAQ-DI improved from 1.67 to 1.20 in TNFi and from 1.33 to 0.84 in csDMARD inadequate responders. ${ }^{117}$ Gossec et al performed another multicentric prospective study in RA patients treated with IV TCZ with the aim to evaluate the percentage of variation of the FACIT fatigue scale from baseline to 4 months. Of 719 patients, 378 patients (62\%) reached MCDI improvement for fatigue, with a very rapid reduction (within 2 weeks). ${ }^{24}$ Finally, in the previously described ACT-ION study, the mean change from baseline was significantly greater in TCZ vs adalimumab-treated patients for both HAQ-DI ( -0.59 vs -0.43 , respectively; $P=0.020)$ and VAS pain $(-32.96$ vs -23.16 , respectively; $P<0.001) .{ }^{86}$ 
Chronic anemia complicating inflammatory diseases can further affect HRQOL in RA patients and IL-6 blockade has been demonstrated to be crucial for improving hemoglobin level in this condition. A subanalysis of MEASURE trial highlighted that treatment with TCZ was associated with reduction of hepcidin level (evident from day $1, P<0.001$ vs placebo) and with the subsequent increase in hemoglobin level (beginning by week 4 and reaching a plateau by week 24). ${ }^{118}$ These data have been recently confirmed by an analysis of a large US care database including 153,788 RA patients, showing that patients with anemia treated with TCZ were $86 \%$ (OR 1.86; 95\% CI 1.43-2.00) more likely to increase hemoglobin of at least $1 \mathrm{~g} / \mathrm{dL}$ at 2 years when compared to other treatments (csDMARDs, bDMARDs, or tofacitinib). ${ }^{119}$

4. The effect on comorbidities: CVD risk and T2DM

The overall impact of IL-6 blockade on CVD risk in RA has been progressively changed during the last decade. In fact, treatment with TCZ since its introduction was known to be involved in the increase of total cholesterol, low-density lipoprotein cholesterol, and high-density lipoprotein cholesterol levels, leading to a warning related to the use in patients with dyslipidemia and increased CVD risk. ${ }^{120}$ However, these modifications have been subsequently interpreted in the context of the so-called "lipid paradox" affecting RA patients. The presence in RA of a chronic inflammatory state produces an increased CVD risk that is inversely associated with cholesterol levels and can be effectively treated with bDMARDs, leading to paradoxical elevation of cholesterol levels in response to their anti-inflammatory effect. ${ }^{121}$ Indeed, cholesterol elevations generally observed since the first weeks of TCZ treatment are not accompanied by a worsening of the atherogenic index, ${ }^{122}$ which is the most accurate predictor of CVD risk especially in RA patients. Moreover, several analyses demonstrated that therapy with TCZ is associated with a strong decrease in CVD incidence, despite the constant change in lipid profile. A post hoc analysis of clinical trial long-term extensions including 3,986 RA patients treated with TCZ (mean treatment duration 3.7 years, with concomitant use of statins in $11.1 \%$ ) showed a very low rate (3.4 events per 1,000 patient years) of major adverse cardiovascular event (MACE). Furthermore, in multivariable model, baseline DAS28 score and higher swollen and tender joints count (but not 24-week lipid changes) were the only predictors of MACE. ${ }^{123}$
Incidence of CV events in TCZ-treated patients was also compared with patients receiving other bDMARDs. The ENTRACTE trial, a Phase IV, multicentric, noninferiority study comparing TCZ $(n=1,538)$ and etanercept $(n=1,542)$ in RA patients with CVD risk factors, showed no significant differences in MACE occurrence between the two groups (HR 1.05; 95\% CI 0.77-1.43) over an average follow-up time of 3.2 years. ${ }^{124}$ Consistently, a recent retrospective cohort study conducted on administrative health care databases of northern Italy showed that TCZ use in RA did not increase the overall risk of acute CV events leading to hospitalization (HR 0.95; 95\% CI 0.54-1.66), when compared to etanercept. ${ }^{125}$

Similar results were observed in two retrospective analyses from the same cohort including three large US insurance claims database, which evaluated a composite cardiovascular outcome (hospitalization for myocardial infarction or stroke) by comparing RA patients receiving TCZ with TNFis in bDMARD failures ${ }^{126}$ or with abatacept as first-line biologic agent. ${ }^{127}$ The observed $\mathrm{CV}$ incidence rates were 0.52 and 0.59 per 100 person years for TCZ vs TNFi, respectively (HR 0.84; 95\% CI $0.56-1.26),{ }^{126}$ and 0.70 and 0.96 per 100 person years for TCZ vs abatacept, respectively (HR 0.82; 95\% CI $0.55-1.22)^{127}$

Only few studies evaluated the effect of TCZ on T2DM. Wu et al demonstrated in 12 mice the protective effects of TCZ against diabetic renal injury, suggesting a correlation with decreased insulin resistance and inhibition of the inflammasome. ${ }^{128}$ A significant reduction of Homeostasis Model Assessment of Insulin Resistance values $(2.97 \pm 0.38-1.99 \pm 0.25, P<0.005)$ was observed after 24 weeks of treatment with TCZ in 24 RA patients, ${ }^{129}$ confirming similar results previously reported by a small study involving 11 RA patients treated with TCZ for 3 months. ${ }^{130}$

Taken together, these data seem to confirm the potential role of IL- 6 inhibitors in the management of RA-related CV risk, which is clearly not increased by lipids elevation induced by TCZ. Moreover, if confirmed by further analyses, the preliminary data regarding the effect on glucose metabolism seem to be very promising for a preferential future use IL-6 blockade in the management of patients with RA complicated by T2DM.

\section{The role of safety profile}

The safety profile of TCZ has been evaluated in several Phase III and IV trials..$^{31,66-71,101,110,131}$ As similarly reported 
in RCTs conducted with other bDMARDs, the most common AEs and serious AEs (SAEs) observed in RA patients receiving TCZ in these trials were infections, such as upper respiratory tract infections, nasopharyngitis, pneumonia, and cellulitis. Other SAEs of interest include gastrointestinal perforations (GIPs), myocardial infarction, stroke, and malignancy. In addition, abnormalities in laboratory test results have also been observed, including decreased neutrophil counts, elevated liver enzyme levels, and increase in lipid levels. No other safety concerns were identified in a cumulative analysis of long-term (4.6 years) TCZ exposure (12,293 patient-years) in the pooled population from 5 Phase III trials compared with the placebo-controlled periods. ${ }^{132}$ Despite concerns for the risk for cancer during immunosuppressive therapy, a long-term evaluation of TCZ Phase III trials did not show any additional risk for overall or sitespecific malignancies above the increased risk expected in RA patients. ${ }^{133}$

The comparative safety profile of TCZ against other bDMARDs does not reveal unexpected issues. In a Cochrane meta-analysis evaluating the incidence of AEs in bDMARDtreated patients, the risk for drug withdrawal because of safety issues was similar across all available bDMARDs. ${ }^{134}$ In particular, no significant difference emerged in the incidence rate of serious infections of TCZ compared to main TNFis, abatacept, or rituximab. Similarly, the 6-month rate of serious infections was similar between adalimumab and TCZ (7\% for both) in the head-to-head trial ADACTA. ${ }^{31}$ In a retrospective cohort study of patients with rheumatic diseases, a higher incidence of neutropenia was observed in TCZ-treated group compared to both abatacept and infliximab (18.6\% vs 3.8\% and 2.8\%, respectively; $P<0.001) .{ }^{135}$ These findings are consistent with the higher incidence of neutropenia reported by comparative analyses of TCZ vs adalimumab from the head-to-head trial ADACTA ${ }^{31}$ and the observational prospective study ACT-ION (12.1\% vs $5.7 \%$ at 52 weeks, respectively). ${ }^{86}$ However, in the whole experience with TCZ, grade 3 or 4 neutropenia was observed only in a small proportion of patients and the decreased neutrophil count during TCZ treatment has not been associated with serious infections. ${ }^{132}$ A higher incidence of GIPs and especially lower intestinal perforations (LIPs) has been observed in TCZ-treated patients compared to those receiving TNFis (GIPs, $1.8-2.8$ vs $0.6-0.9$ per 1,000 patient-years, respectively; LIPs, $1.26-2.7$ vs $0.2-0.76$ per 1,000 patient-years, respectively). ${ }^{136-138}$ In particular, the risk for LIPs seemed to be greater in patients with a history of diverticulitis, suggesting to avoid TCZ in patients carrying this comorbidity. ${ }^{136,137}$

\section{Conclusion}

Extensive experience in RCTs and real-world settings over the last decade has firmly established the short- and long-term efficacy of both IV and SC TCZ in adults with moderate-tosevere RA who failed synthetic or biologic DMARDs. The clinical response and the effect of radiographic progression were consistent across RA subsets, confirming the current main indications of TCZ in MTX and TNFis inadequate responders. Furthermore, the widespread effect on RA pathogenetic network of IL-6 compared to TNF blockade is crucial for the superiority as monotherapy of TCZ over TNFis demonstrated in clinical trials. Based on this clear evidence, IL-6 inhibition along with JAK blockade is now the mechanism of action suggested by EULAR recommendations to be used in patients with contraindications/intolerance to MTX.

The favorable results from TCZ long-term and real-life experiences are reassuring about the initial concerns for safety issues, such as serious infections, liver toxicity, and neutropenia, while history of diverticulitis still remains the major contraindication to the prescription of the drug. Considering the need for strategic tools to be applied in a personalized approach and the lack of specific biomarkers, the central role of IL-6 in the pathogenesis of RA and in the development of articular and extra-articular manifestations of the disease may provide some useful drivers toward precision medicine. The very early involvement of IL-6 in first phase of RA may suggest to anticipate the introduction of TCZ in newly diagnosed disease, as the impressive results of the U-ACT Early trial seem to clearly confirm (more than $90 \%$ on remission rate). Moreover, extra-articular features such as pain, fatigue, depression, and anemia seem to be strictly related to IL-6, suggesting the preferential use of TCZ in patients presenting a systemic pattern of RA. In addition, comorbidities such as increased CVD risk and T2DM seem to be effectively managed by the use of IL-6 blockade, giving another potential driver for the choice of TCZ.

\section{Author contributions}

EGF designed the review methods and drafted and revised the paper. $\mathrm{MB}, \mathrm{CC}$, and $\mathrm{AB}$ drafted and revised the paper. All authors contributed toward data analysis, drafting and revising the paper, gave final approval of the version to be published and agree to be accountable for all aspects of the work.

\section{Disclosure}

EGF served as a consultant and/or speaker for BMS, Lilly, Roche, Celgene, MSD, UCB, Pfizer, Janssen, Novartis, Sanofi-Genzyme, and Abbvie. The authors report no other conflicts of interest in this work. 


\section{References}

1. McInnes IB, Schett G. The pathogenesis of rheumatoid arthritis. N Engl J Med Overseas Ed. 2011;365(23):2205-2219.

2. Smolen JS, Aletaha D, McInnes IB. Rheumatoid arthritis. Lancet. 2016;388(10055):2023-2038.

3. Smolen JS, Breedveld FC, Burmester GR, et al. Treating rheumatoid arthritis to target: 2014 update of the recommendations of an international task force. Ann Rheum Dis. 2016;75(1):3-15.

4. Smolen JS, Aletaha D, Redlich K. The pathogenesis of rheumatoid arthritis: new insights from old clinical data? Nat Rev Rheumatol. 2012; 8(4):235-243

5. McInnes IB, Buckley CD, Isaacs JD. Cytokines in rheumatoid arthritis - shaping the immunological landscape. Nat Rev Rheumatol. 2016;12(1):63-68.

6. Smolen JS, Landewé R, Bijlsma J, et al. EULAR recommendations for the management of rheumatoid arthritis with synthetic and biological disease-modifying antirheumatic drugs: 2016 update. Ann Rheum Dis. 2017;76(6):960-977.

7. Singh JA, Saag KG, Bridges SL, et al. American College of Rheumatology guideline for the treatment of rheumatoid arthritis. Arthritis Rheumatol. 2016;68(1):1-26.

8. Nam JL, Takase-Minegishi K, Ramiro S, et al. Efficacy of biological disease-modifying antirheumatic drugs: a systematic literature review informing the 2016 update of the EULAR recommendations for the management of rheumatoid arthritis. Ann Rheum Dis. 2017; 76(6):1113-1136.

9. Marchesoni A, Zaccara E, Gorla R, et al. TNF- $\alpha$ antagonist survival rate in a cohort of rheumatoid arthritis patients observed under conditions of standard clinical practice. Ann N Y Acad Sci. 2009;1173(1):837-846.

10. Favalli EG, Pregnolato F, Biggioggero M, et al. Twelve-year retention rate of first-line tumor necrosis factor inhibitors in rheumatoid arthritis: real-life data from a local registry. Arthritis Care Res. 2016;68(4): 432-439.

11. Favalli EG, Raimondo MG, Becciolini A, Crotti C, Biggioggero M, Caporali R. The management of first-line biologic therapy failures in rheumatoid arthritis: current practice and future perspectives. Autoimmun Rev. 2017;16(12):1185-1195.

12. Choy E. Understanding the dynamics: pathways involved in the pathogenesis of rheumatoid arthritis. Rheumatology. 2012;51(Suppl 5): $\mathrm{v} 3-\mathrm{v} 11$.

13. Dayer J-M, Choy E. Therapeutic targets in rheumatoid arthritis: the interleukin-6 receptor. Rheumatology. 2010;49(1):15-24.

14. Raimondo MG, Biggioggero M, Crotti C, Becciolini A, Favalli EG. Profile of sarilumab and its potential in the treatment of rheumatoid arthritis. Drug Des Devel Ther. 2017;11:1593-1603.

15. Rose-John S, Winthrop K, Calabrese L. The role of IL-6 in host defence against infections: immunobiology and clinical implications. Nat Rev Rheumatol. 2017;13(7):399-409.

16. Wolf J, Rose-John S, Garbers C. Interleukin-6 and its receptors: a highly regulated and dynamic system. Cytokine. 2014;70(1):11-20.

17. Johnson DE, O'Keefe RA, Grandis JR. Targeting the IL-6/JAK/ STAT3 signalling axis in cancer. Nat Rev Clin Oncol. 2018;15(4): 234-248.

18. Anaya J-M, Duarte-Rey C, Sarmiento-Monroy JC, Bardey D, Castiblanco J, Rojas-Villarraga A. Personalized medicine. Closing the gap between knowledge and clinical practice. Autoimmun Rev. 2016; 15(8):833-842.

19. Selmi C, Kon E, Santis MD, et al. How advances in personalized medicine will change rheumatology. Per Med. 2018;15(2):75-78.

20. Kiely PDW. Biologic efficacy optimization - a step towards personalized medicine. Rheumatology. 2016;55(5):780-788.

21. Cantini F, Niccoli L, Nannini C, et al. Tailored first-line biologic therapy in patients with rheumatoid arthritis, spondyloarthritis, and psoriatic arthritis. Semin Arthritis Rheum. 2016;45(5):519-532.

22. Cantini F, Niccoli L, Nannini C, et al. Second-line biologic therapy optimization in rheumatoid arthritis, psoriatic arthritis, and ankylosing spondylitis. Semin Arthritis Rheum. 2017;47(2):183-192.
23. Fonseca JE, Santos MJ, Canhão H, Choy E. Interleukin-6 as a key player in systemic inflammation and joint destruction. Autoimmun Rev. 2009;8(7):538-542.

24. Gossec L, Steinberg G, Rouanet S, Combe B. Fatigue in rheumatoid arthritis: quantitative findings on the efficacy of tocilizumab and on factors associated with fatigue. The French multicentre prospective PEPS Study. Clin Exp Rheumatol. 2015;33(5):664-670.

25. Song S-NJ, Tomosugi N, Kawabata H, Ishikawa T, Nishikawa T, Yoshizaki K. Down-regulation of hepcidin resulting from long-term treatment with an anti-IL-6 receptor antibody (tocilizumab) improves anemia of inflammation in multicentric Castleman disease. Blood. 2010;116(18):3627-3634.

26. Abdel Meguid MH, Hamad YH, Swilam RS, Barakat MS. Relation of interleukin- 6 in rheumatoid arthritis patients to systemic bone loss and structural bone damage. Rheumatol Int. 2013;33(3):697-703.

27. Choy EHS, Calabrese LH. Neuroendocrine and neurophysiological effects of interleukin 6 in rheumatoid arthritis. Rheumatology. 2018; 57(11):1885-1895.

28. Fève B, Bastard J-P. The role of interleukins in insulin resistance and type 2 diabetes mellitus. Nat Rev Endocrinol. 2009;5(6):305-311.

29. Danesh J, Kaptoge S, Mann AG, et al. Long-term interleukin-6 levels and subsequent risk of coronary heart disease: two new prospective studies and a systematic review. PLoS Med. 2008;5(4):e78.

30. Ridker PM, Rifai N, Stampfer MJ, Hennekens CH. Plasma concentration of interleukin- 6 and the risk of future myocardial infarction among apparently healthy men. Circulation. 2000;101(15):1767-1772.

31. Gabay C, Emery P, van Vollenhoven R, et al. Tocilizumab monotherapy versus adalimumab monotherapy for treatment of rheumatoid arthritis (ADACTA): a randomised, double-blind, controlled phase 4 trial. Lancet. 2013;381(9877):1541-1550.

32. Burmester GR, Lin Y, Patel R, et al. Efficacy and safety of sarilumab monotherapy versus adalimumab monotherapy for the treatment of patients with active rheumatoid arthritis (MONARCH): a randomised, double-blind, parallel-group phase III trial. Ann Rheum Dis. 2017; 76(5):840-847.

33. Kishimoto T. IL-6: from laboratory to bedside. Clin Rev Allergy Immunol. 2005;28(3):177-186.

34. Tanaka T, Kishimoto T. The biology and medical implications of interleukin-6. Cancer Immunol Res. 2014;2(4):288-294.

35. Muraguchi A, Hirano T, Tang B, et al. The essential role of B cell stimulatory factor 2 (BSF-2/IL-6) for the terminal differentiation of B cells. J Exp Med. 1988;167(2):332-344.

36. Jego G, Bataille R, Pellat-Deceunynck C. Interleukin-6 is a growth factor for nonmalignant human plasmablasts. Blood. 2001;97(6): 1817-1822.

37. Kimura A, Kishimoto T. IL-6: regulator of Treg/Th17 balance. Eur J Immunol. 2010;40(7):1830-1835.

38. Bettelli E, Carrier Y, Gao W, et al. Reciprocal developmental pathways for the generation of pathogenic effector $\mathrm{TH} 17$ and regulatory $\mathrm{T}$ cells. Nature. 2006;441(7090):235-238.

39. Veldhoen M, Hocking RJ, Atkins CJ, Locksley RM, Stockinger B. TGF $\beta$ in the context of an inflammatory cytokine milieu supports de novo differentiation of IL-17-producing T Cells. Immunity. 2006;24(2): $179-189$.

40. Castell JV, Gómez-Lechón MJ, David M, Fabra R, Trullenque R, Heinrich PC. Acute-phase response of human hepatocytes: regulation of acute-phase protein synthesis by interleukin-6. Hepatology. 1990; 12(5):1179-1186.

41. Heinrich PC, Castell JV, Andus T. Interleukin-6 and the acute phase response. Biochem J. 1990;265(3):621-636.

42. Bartok B, Firestein GS. Fibroblast-like synoviocytes: key effector cells in rheumatoid arthritis. Immunol Rev. 2010;233(1):233-255.

43. Gabay C. Interleukin-6 and chronic inflammation. Arthritis Res Ther. 2006;8(Suppl 2):S3

44. Hein GE, Köhler M, Oelzner P, Stein G, Franke S. The advanced glycation end product pentosidine correlates to IL-6 and other relevant inflammatory markers in rheumatoid arthritis. Rheumatol Int. 2005; 26(2):137-141. 
45. Abe H, Sakai T, Ando W, et al. Synovial joint fluid cytokine levels in hip disease. Rheumatology. 2014;53(1):165-172.

46. Desgeorges A, Gabay C, Silacci P, et al. Concentrations and origins of soluble interleukin 6 receptor-alpha in serum and synovial fluid. J Rheumatol. 1997;24(8):1510-1516.

47. Dasgupta B, Corkill M, Kirkham B, Gibson T, Panayi G. Serial estimation of interleukin 6 as a measure of systemic disease in rheumatoid arthritis. J Rheumatol. 1992;19(1):22-25.

48. Kishimoto $T$. Interleukin-6: from basic science to medicine -40 years in immunology. Аnпu Rev Immunol. 2005;23(1):1-21.

49. Lally F, Smith E, Filer A, et al. A novel mechanism of neutrophil recruitment in a coculture model of the rheumatoid synovium. Arthritis Rheum. 2005;52(11):3460-3469.

50. Kaplanski G, Marin V, Montero-Julian F, Mantovani A, Farnarier C. IL-6: a regulator of the transition from neutrophil to monocyte recruitment during inflammation. Trends Immunol. 2003;24(1):25-29.

51. Hashizume M, Hayakawa N, Mihara M. IL-6 trans-signalling directly induces RANKL on fibroblast-like synovial cells and is involved in RANKL induction by TNF- and IL-17. Rheumatology. 2008;47(11):1635-1640.

52. Rose-John S. IL-6 trans-signaling via the soluble IL-6 receptor: importance for the pro-inflammatory activities of IL-6. Int J Biol Sci. 2012;8(9):1237-1247.

53. Rose-John S, Scheller J, Elson G, Jones SA. Interleukin-6 biology is coordinated by membrane-bound and soluble receptors: role in inflammation and cancer. J Leukoc Biol. 2006;80(2):227-236.

54. März P, Cheng J-G, Gadient RA, et al. Sympathetic neurons can produce and respond to interleukin 6. Proc Natl Acad Sci U S A. 1998; 95(6):3251-3256.

55. Obreja O, Biasio W, Andratsch M, et al. Fast modulation of heatactivated ionic current by proinflammatory interleukin 6 in rat sensory neurons. Brain. 2005;128(7):1634-1641.

56. Mastorakos G, Chrousos GP, Weber JS. Recombinant interleukin-6 activates the hypothalamic-pituitary-adrenal axis in humans. $J$ Clin Endocrinol Metab. 1993;77(6):1690-1694.

57. Eijsbouts AM, van den Hoogen FH, Laan RF, Hermus AR, Sweep CG, van de Putte LB. Hypothalamic-pituitary-adrenal axis activity in patients with rheumatoid arthritis. Clin Exp Rheumatol. 2005;23(5):658-664.

58. Jones SA, Richards PJ, Scheller J, Rose-John S. IL-6 transsignaling: the in vivo consequences. J Interferon Cytokine Res. 2005;25(5): 241-253.

59. Tanaka T, Narazaki M, Kishimoto T. IL-6 in inflammation, immunity, and disease. Cold Spring Harb Perspect Biol. 2014;6(10):a016295.

60. Nemeth E, Tuttle MS, Powelson J, et al. Hepcidin regulates cellular iron efflux by binding to ferroportin and inducing its internalization. Science. 2004;306(5704):2090-2093.

61. Weiss G, Schett G. Anaemia in inflammatory rheumatic diseases. Nat Rev Rheumatol. 2013;9(4):205-215.

62. Choy E, Ganeshalingam K, Semb AG, Szekanecz Z, Nurmohamed M. Cardiovascular risk in rheumatoid arthritis: recent advances in the understanding of the pivotal role of inflammation, risk predictors and the impact of treatment. Rheumatology. 2014;53(12):2143-2154.

63. Ridker PM, Hennekens CH, Buring JE, Rifai N. C-reactive protein and other markers of inflammation in the prediction of cardiovascular disease in women. $N$ Engl J Med Overseas Ed. 2000;342(12):836-843.

64. Roche Registration Ltd. RoActemra $20 \mathrm{mg} / \mathrm{ml}$ Concentrate for Solution for Infusion. Welwynn Garden City: Roche Registration Ltd; 2014.

65. Genentech Inc. Actemra (tocilizumab) Injection for Intravenous Infusion. South San Francisco: Genentech, Inc.; 2017.

66. Kremer JM, Blanco R, Brzosko M, et al. Tocilizumab inhibits structural joint damage in rheumatoid arthritis patients with inadequate responses to methotrexate: results from the double-blind treatment phase of a randomized placebo-controlled trial of tocilizumab safety and prevention of structu. Arthritis Rheum. 2011;63(3):609-621.

67. Jones G, Sebba A, Gu J, et al. Comparison of tocilizumab monotherapy versus methotrexate monotherapy in patients with moderate to severe rheumatoid arthritis: the AMBITION study. Ann Rheum Dis. 2010; 69(01):88-96.
68. Emery P, Keystone E, Tony HP, et al. IL-6 receptor inhibition with tocilizumab improves treatment outcomes in patients with rheumatoid arthritis refractory to anti-tumour necrosis factor biologicals: results from a 24-week multicentre randomised placebo-controlled trial. Ann Rheum Dis. 2008;67(11):1516-1523.

69. Genovese MC, McKay JD, Nasonov EL, et al. Interleukin-6 receptor inhibition with tocilizumab reduces disease activity in rheumatoid arthritis with inadequate response to disease-modifying antirheumatic drugs: the tocilizumab in combination with traditional diseasemodifying antirheumatic drug therapy study. Arthritis Rheum. 2008; 58(10):2968-2980.

70. Smolen JS, Beaulieu A, Rubbert-Roth A, et al. Effect of interleukin-6 receptor inhibition with tocilizumab in patients with rheumatoid arthritis (OPTION study): a double-blind, placebo-controlled, randomised trial. Lancet. 2008;371(9617):987-997.

71. Kivitz A, Olech E, Borofsky M, et al. Subcutaneous tocilizumab versus placebo in combination with disease-modifying antirheumatic drugs in patients with rheumatoid arthritis. Arthritis Care Res. 2014; 66(11): 1653-1661.

72. Burmester GR, Rubbert-Roth A, Cantagrel A, et al. A randomised, double-blind, parallel-group study of the safety and efficacy of subcutaneous tocilizumab versus intravenous tocilizumab in combination with traditional disease-modifying antirheumatic drugs in patients with moderate to severe rheumatoid arthritis (SUMMACTA study). Ann Rheum Dis. 2014;73(1):69-74.

73. Gabay C, Riek M, Hetland ML, et al. Effectiveness of tocilizumab with and without synthetic disease-modifying antirheumatic drugs in rheumatoid arthritis: results from a European collaborative study. Ann Rheum Dis. 2016;75(7):1336-1342.

74. Lauper K, Nordström DC, Pavelka K, et al. Comparative effectiveness of tocilizumab versus TNF inhibitors as monotherapy or in combination with conventional synthetic disease-modifying antirheumatic drugs in patients with rheumatoid arthritis after the use of at least one biologic disease-modifying antirheumatic drug: analyses from the panEuropean TOCERRA register collaboration. Ann Rheum Dis. 2018; 77(9):1276-1282.

75. Iannone F, Ferraccioli G, Sinigaglia L, et al. Real-world experience of tocilizumab in rheumatoid arthritis: sub-analysis of data from the Italian biologics' register GISEA. Clin Rheumatol. 2018;37(2):315-321.

76. Iannazzo S, Benucci M, Favalli EG. Tocilizumab after a first-line with anti-TNF in rheumatoid arthritis: a cost-consequence analysis in the Italian setting. Clin Exp Rheumatol. 2018;36(3):479-485.

77. Nishimoto N, Yoshizaki K, Miyasaka N, et al. Treatment of rheumatoid arthritis with humanized anti-interleukin-6 receptor antibody: a multicenter, double-blind, placebo-controlled trial. Arthritis Rheum. 2004;50(6):1761-1769.

78. Yazici Y, Curtis JR, Ince A, et al. Efficacy of tocilizumab in patients with moderate to severe active rheumatoid arthritis and a previous inadequate response to disease-modifying antirheumatic drugs: the ROSE study. Ann Rheum Dis. 2012;71(2):198-205.

79. Singh JA, Beg S, Lopez-Olivo MA. Tocilizumab for rheumatoid arthritis: a Cochrane systematic review. J Rheumatol. 2011;38(1): 10-20.

80. Bergman GJD, Hochberg MC, Boers M, Wintfeld N, Kielhorn A, Jansen JP. Indirect comparison of tocilizumab and other biologic agents in patients with rheumatoid arthritis and inadequate response to disease-modifying antirheumatic drugs. Semin Arthritis Rheum. 2010; 39(6):425-441.

81. Bykerk VP, Östör AJK, Alvaro-Gracia J, et al. Tocilizumab in patients with active rheumatoid arthritis and inadequate responses to DMARDs and/or TNF inhibitors: a large, open-label study close to clinical practice. Ann Rheum Dis. 2012;71(12):1950-1954.

82. Iking-Konert C, von Hinüber U, Richter C, et al. ROUTINE - a prospective, multicentre, non-interventional, observational study to evaluate the safety and effectiveness of intravenous tocilizumab for the treatment of active rheumatoid arthritis in daily practice in Germany. Rheumatology. 2016;55(4):624-635. 
83. Balsa A, Tovar Beltrán JV, Cáliz Cáliz R, et al. Patterns of use and dosing of tocilizumab in the treatment of patients with rheumatoid arthritis in routine clinical practice: the ACT-LIFE study. Rheumatol Int. 2015;35(9):1525-1534.

84. Kihara M, Davies R, Kearsley-Fleet L, et al. Use and effectiveness of tocilizumab among patients with rheumatoid arthritis: an observational study from the British Society for Rheumatology Biologics Register for rheumatoid arthritis. Clin Rheumatol. 2017;36(2):241-250.

85. Backhaus M, Kaufmann J, Richter C, et al. Comparison of tocilizumab and tumour necrosis factor inhibitors in rheumatoid arthritis: a retrospective analysis of 1603 patients managed in routine clinical practice. Clin Rheumatol. 2015;34(4):673-681.

86. Choy EH, Bernasconi C, Aassi M, Molina JF, Epis OM. Treatment of rheumatoid arthritis with anti-tumor necrosis factor or tocilizumab therapy as first biologic agent in a global comparative observational Study. Arthritis Care Res. 2017;69(10):1484-1494.

87. Dennis G, Holweg CTJ, Kummerfeld SK, et al. Synovial phenotypes in rheumatoid arthritis correlate with response to biologic therapeutics. Arthritis Res Ther. 2014;16(2):R90.

88. Gremese E, Carletto A, Padovan M, et al. Obesity and reduction of the response rate to anti-tumor necrosis factor $\alpha$ in rheumatoid arthritis: an approach to a personalized medicine. Arthritis Care Res. 2013;65(1): 94-100.

89. Hyrich KL, Watson KD, Silman AJ, Symmons DP; The BSR Biologics Register. Predictors of response to anti-TNF-alpha therapy among patients with rheumatoid arthritis: results from the British Society for Rheumatology Biologics Register. Rheumatology. 2006;45(12): 1558-1565.

90. Sokolove J, Schiff M, Fleischmann R, et al. Impact of baseline anti-cyclic citrullinated peptide- 2 antibody concentration on efficacy outcomes following treatment with subcutaneous abatacept or adalimumab: 2-year results from the AMPLE trial. Ann Rheum Dis. 2016;75(4):709-714.

91. Isaacs JD, Cohen SB, Emery P, et al. Effect of baseline rheumatoid factor and anticitrullinated peptide antibody serotype on rituximab clinical response: a meta-analysis. Ann Rheum Dis. 2013;72(3):329-336.

92. Martin-Mola E, Balsa A, García-Vicuna R, et al. Anti-citrullinated peptide antibodies and their value for predicting responses to biologic agents: a review. Rheumatol Int. 2016;36(8):1043-1063.

93. Pers Y-M, Godfrin-Valnet M, Lambert J, et al. Response to tocilizumab in rheumatoid arthritis is not influenced by the body mass index of the patient. J Rheumatol. 2015;42(4):580-584.

94. Theander E, Proven A, Fallang A, Svelander L, Trollmo T. FRI0163 smoking status does not seem to affect tocilizumab efficacy in RA patients. Ann Rheum Dis. 2015;74(Suppl 2):482.

95. Narváez J, Magallares B, Díaz Torné C, et al. Predictive factors for induction of remission in patients with active rheumatoid arthritis treated with tocilizumab in clinical practice. Semin Arthritis Rheum. 2016; 45(4):386-390.

96. Wang J, Devenport J, Low JM, Yu D, Hitraya E. Relationship between baseline and early changes in c-reactive protein and interleukin-6 levels and clinical response to tocilizumab in rheumatoid arthritis. Arthritis Care Res. 2016;68(6):882-885.

97. Diaz-Torne C, Ortiz MDA, Moya P, et al. The combination of IL-6 and its soluble receptor is associated with the response of rheumatoid arthritis patients to tocilizumab. Semin Arthritis Rheum. 2018; 47(6):757-764.

98. Nakagawa J, Koyama Y, Kawakami A, et al. A novel scoring system based on common laboratory tests predicts the efficacy of TNF-inhibitor and IL- 6 targeted therapy in patients with rheumatoid arthritis: a retrospective, multicenter observational study. Arthritis Res Ther. 2017;19(1): 185 .

99. Giacomelli R, Afeltra A, Alunno A, et al. International consensus: what else can we do to improve diagnosis and therapeutic strategies in patients affected by autoimmune rheumatic diseases (rheumatoid arthritis, spondyloarthritides, systemic sclerosis, systemic lupus erythematosus, antiphospholipid syndrome and Sjogren's syndrome)? Autoimmun Rev. 2017;16(9):911-924.
100. Monti S, Klersy C, Gorla R, et al. Factors influencing the choice of first- and second-line biologic therapy for the treatment of rheumatoid arthritis: real-life data from the Italian LORHEN Registry. Clin Rheumatol. 2017;36(4):753-761.

101. Burmester GR, Rigby WF, van Vollenhoven RF, et al. Tocilizumab in early progressive rheumatoid arthritis: FUNCTION, a randomised controlled trial. Ann Rheum Dis. 2016;75(6):1081-1091.

102. Burmester GR, Rigby WF, van Vollenhoven RF, et al. Tocilizumab combination therapy or monotherapy or methotrexate monotherapy in methotrexate-naive patients with early rheumatoid arthritis: 2-year clinical and radiographic results from the randomised, placebo-controlled FUNCTION trial. Ann Rheum Dis. 2017;76(7): 1279-1284

103. Bijlsma JWJ, Welsing PMJ, Woodworth TG, et al. Early rheumatoid arthritis treated with tocilizumab, methotrexate, or their combination (U-Act-Early): a multicentre, randomised, doubleblind, double-dummy, strategy trial. Lancet. 2016;388(10042): 343-355.

104. Favalli EG, Biggioggero M, Meroni PL. Methotrexate for the treatment of rheumatoid arthritis in the biologic era: still an "anchor" drug? Autoimmun Rev. 2014;13(11):1102-1108.

105. Favalli EG, Becciolini A, Biggioggero M, et al. The role of concomitant methotrexate dosage and maintenance over time in the therapy of rheumatoid arthritis patients treated with adalimumab or etanercept: retrospective analysis of a local registry. Drug Des Devel Ther. 2018; 12:1421-1429.

106. Kalden JR, Schulze-Koops H. Immunogenicity and loss of response to TNF inhibitors: implications for rheumatoid arthritis treatment. Nat Rev Rheumatol. 2017;13(12):707-718.

107. Emery P, Sebba A, Huizinga TW. Biologic and oral disease-modifying antirheumatic drug monotherapy in rheumatoid arthritis. Ann Rheum Dis. 2013;72(12):1897-1904.

108. Choy E, Aletaha D, Behrens F, et al. Monotherapy with biologic disease-modifying anti-rheumatic drugs in rheumatoid arthritis. Rheumatology. 2017;56(5):689-697.

109. Jones G, Wallace T, Mcintosh MJ, Brockwell L, Gómez-Reino JJ, Sebba A. Five-year efficacy and safety of tocilizumab monotherapy in patients with rheumatoid arthritis who were methotrexate- and biologic-naive or free of methotrexate for 6 months: the AMBITION Study. J Rheumatol. 2017;44(2):142-146.

110. Dougados M, Kissel K, Conaghan PG, et al. Clinical, radiographic and immunogenic effects after 1 year of tocilizumab-based treatment strategies in rheumatoid arthritis: the ACT-RAY study. Ann Rheum Dis. 2014;73(5):803-809.

111. Choy E, Caporali R, Xavier R, et al. Subcutaneous tocilizumab in rheumatoid arthritis: findings from the common-framework phase 4 study programme TOZURA conducted in 22 countries. Rheumatology. 2018;57(6):1129.

112. O’Mahony A, John MR, Cho H, Hashizume M, Choy EH. Discriminating phenotypic signatures identified for tocilizumab, adalimumab, and tofacitinib monotherapy and their combinations with methotrexate. J Transl Med. 2018;16(1):156.

113. Kirwan JR, Hewlett SE, Heiberg T, et al. Incorporating the patient perspective into outcome assessment in rheumatoid arthritis - progress at OMERACT 7. J Rheumatol. 2005;32(11):2250-2256.

114. Crotti C, Biggioggero M, Becciolini A, Favalli EG. Sarilumab: patientreported outcomes in rheumatoid arthritis. Patient Relat Outcome Meas. 2018;9:275-284.

115. Strand V, Michalska M, Birchwood C, et al. Impact of tocilizumab monotherapy on patient-reported outcomes in patients with rheumatoid arthritis from two randomised controlled trials. RMD Open. 2017;3(2):e000496.

116. Strand V, Michalska M, Birchwood C, et al. Impact of tocilizumab administered intravenously or subcutaneously on patient-reported quality-of-life outcomes in patients with rheumatoid arthritis. $R M D$ Open. 2018;4(1):e00602. 
117. Burmester GR, Feist E, Kellner H, Braun J, Iking-Konert C, RubbertRoth A. Effectiveness and safety of the interleukin 6-receptor antagonist tocilizumab after 4 and 24 weeks in patients with active rheumatoid arthritis: the first phase IIIb real-life study (TAMARA). Ann Rheum Dis. 2011;70(5):755-759.

118. Isaacs JD, Harari O, Kobold U, Lee JS, Bernasconi C. Effect of tocilizumab on haematological markers implicates interleukin-6 signalling in the anaemia of rheumatoid arthritis. Arthritis Res Ther. 2013; 15(6):R204.

119. Paul SK, Montvida O, Best JH, Gale S, Pethoe-Schramm A, Sarsour K. Effectiveness of biologic and non-biologic antirheumatic drugs on anaemia markers in 153,788 patients with rheumatoid arthritis: new evidence from real-world data. Semin Arthritis Rheum. 2018;47(4): $478-484$

120. Singh JA, Beg S, Lopez-Olivo MA. Tocilizumab for rheumatoid arthritis. Cochrane Database Syst Rev. 2010;(7):CD008331.

121. Choy E, Sattar N. Interpreting lipid levels in the context of high-grade inflammatory states with a focus on rheumatoid arthritis: a challenge to conventional cardiovascular risk actions. Ann Rheum Dis. 2009; 68(4):460-469

122. Nishimoto N, Ito K, Takagi N. Safety and efficacy profiles of tocilizumab monotherapy in Japanese patients with rheumatoid arthritis: meta-analysis of six initial trials and five long-term extensions. Mod Rheumatol. 2010;20(3):222-232.

123. Rao VU, Pavlov A, Klearman M, et al. An evaluation of risk factors for major adverse cardiovascular events during tocilizumab therapy. Arthritis Rheumatol. 2015;67(2):372-380.

124. Giles JT, Sattar N, Gabriel SE, et al. Comparative cardiovascular safety of tocilizumab vs etanercept in rheumatoid arthritis: results of a randomized, parallel-group, multicenter, noninferiority, phase 4 clinical trial. Arthritis Rheumatol. 2016;68(Suppl 10):4357-4359.

125. Generali E, Carrara G, Selmi C, et al. Comparison of the risks of hospitalisation for cardiovascular events in patients with rheumatoid arthritis treated with tocilizumab and etanercept. Clin Exp Rheumatol. 2018;36(2):310-313.

126. Kim SC, Solomon DH, Rogers JR, et al. Cardiovascular safety of tocilizumab versus tumor necrosis factor inhibitors in patients with rheumatoid arthritis: a multi-database cohort study. Arthritis Rheumatol. 2017;69(6):1154-1164

127. Kim SC, Solomon DH, Rogers JR, et al. No difference in cardiovascular risk of tocilizumab versus abatacept for rheumatoid arthritis: a multi-database cohort study. Semin Arthritis Rheum. 2018. Epub March 22, 2018.
128. Wu R, Liu X, Yin J, et al. IL-6 receptor blockade ameliorates diabetic nephropathy via inhibiting inflammasome in mice. Metabolism. 2018;83:18-24.

129. Chen DY, Chen YM, Hsieh TY, Hsieh CW, Lin CC, Lan JL. Significant effects of biologic therapy on lipid profiles and insulin resistance in patients with rheumatoid arthritis. Arthritis Res Ther. 2015; 17:52.

130. Schultz O, Oberhauser F, Saech J, et al. Effects of inhibition of interleukin-6 signalling on insulin sensitivity and lipoprotein (a) levels in human subjects with rheumatoid diseases. PLoS One. 2010;5(12):e14328.

131. Burmester GR, Rubbert-Roth A, Cantagrel A, et al. Efficacy and safety of subcutaneous tocilizumab versus intravenous tocilizumab in combination with traditional DMARDs in patients with RA at week 97 (SUMMACTA). Ann Rheum Dis. 2016;75(1):68-74.

132. Genovese MC, Rubbert-Roth A, Smolen JS, et al. Longterm safety and efficacy of tocilizumab in patients with rheumatoid arthritis: a cumulative analysis of up to 4.6 years of exposure. J Rheumatol. 2013;40(6): 768-780.

133. Rubbert-Roth A, Sebba A, Brockwell L, et al. Malignancy rates in patients with rheumatoid arthritis treated with tocilizumab. RMD Open. 2016;2(1):e000213.

134. Singh JA, Wells GA, Christensen R, et al. Adverse effects of biologics: a network meta-analysis and Cochrane overview. Cochrane Database Syst Rev. 2011;(2):CD008794.

135. Espinoza F, Le Blay P, Combe B. Biologic disease-modifying antirheumatic drug (bDMARD)-induced neutropenia: a registry from a retrospective cohort of patients with rheumatic diseases treated with 3 classes of intravenous bDMARD. J Rheumatol. 2017;44(6): 844-849.

136. Strangfeld A, Richter A, Siegmund B, et al. Risk for lower intestinal perforations in patients with rheumatoid arthritis treated with tocilizumab in comparison to treatment with other biologic or conventional synthetic DMARDs. Ann Rheum Dis. 2017;76(3):504-510.

137. Xie F, Yun H, Bernatsky S, Curtis JR. Brief report: risk of gastrointestinal perforation among rheumatoid arthritis patients receiving tofacitinib, tocilizumab, or other biologic treatments. Arthritis Rheumatol. 2016;68(11):2612-2617.

138. Monemi S, Berber E, Sarsour K, et al. Incidence of gastrointestinal perforations in patients with rheumatoid arthritis treated with tocilizumab from clinical trial, postmarketing, and real-world data sources. Rheumatol Ther. 2016;3(2):337-352.
Drug Design, Development and Therapy

\section{Publish your work in this journal}

Drug Design, Development and Therapy is an international, peerreviewed open-access journal that spans the spectrum of drug design and development through to clinical applications. Clinical outcomes, patient safety, and programs for the development and effective, safe, and sustained use of medicines are the features of the journal, which
Dovepress

has also been accepted for indexing on PubMed Central. The manuscript management system is completely online and includes a very quick and fair peer-review system, which is all easy to use. Visit http://www.dovepress.com/testimonials.php to read real quotes from published authors. 